\title{
MRI Investigation of New Approach to Improve the Recovery of Myocardial Ischemia Reperfusion Injury by Treatment with Intralipid ${ }^{\circledR}$
}

\author{
Yijen L. Wu1,2, Li Liu3 ${ }^{3}$ Fang-Cheng Yeh4, Bedda L. Rosario5, Chien Ho ${ }^{3 *}$ \\ ${ }^{1}$ Rangos Research Center Animal Imaging Core, Children's Hospital of Pittsburgh of University of Pittsburgh Medical Center, Pittsburgh, \\ PA, USA \\ ${ }^{2}$ Department of Developmental Biology, School of Medicine, University of Pittsburgh, Pittsburgh, PA, USA \\ ${ }^{3}$ Department of Biological Sciences, Carnegie Mellon University, Pittsburgh, PA, USA \\ ${ }^{4}$ Department of Neurological Surgery, University of Pittsburgh, Pittsburgh, PA, USA \\ ${ }^{5}$ Department of Epidemiology, University of Pittsburgh, Pittsburgh, PA, USA \\ Email: yijenwu@pitt.edu, liliu@andrew.cmu.edu, frank.yeh@gmail.com,1r5@pitt.edu, ${ }^{*}$ chienho@andrew.cmu.edu
}

How to cite this paper: Wu, Y.L., Liu, L., Yeh, F.-C., Rosario, B.L. and Ho, C. (2016) MRI Investigation of New Approach to Improve the Recovery of Myocardial Ischemia Reperfusion Injury by Treatment with Intralipid $^{\oplus}$. World Journal of Cardiovascular Diseases, 6, 352-371. http://dx.doi.org/10.4236/wjcd.2016.610041

Received: September 1, 2016

Accepted: October 7, 2016

Published: October 10, 2016

Copyright $\odot 2016$ by authors and Scientific Research Publishing Inc. This work is licensed under the Creative Commons Attribution International License (CC BY 4.0).

http://creativecommons.org/licenses/by/4.0/ (c) (i) Open Access

\section{Abstract}

Background: Despite advances in revascularization and thrombolytic therapy, the outcome of patients after acute myocardial infarction (MI) could be complicated by ischemia reperfusion injury (IRI) and subsequent ventricular remodeling. Inflammation plays a central role in IRI. Intralipid ${ }^{\circledR}$ has been shown to reduce infarct size after IRI, but its effects on myocardial inflammation have not been addressed. The goal of this study is to investigate the effects of Intralipid ${ }^{\circledR}$ on in-situ myocardial inflammation and to better characterize its cardio-protective effects. Methods and Results: Cellular MRI was used to evaluate myocardial inflammation of iron-oxide-labeled macrophage infiltration. Cardiac MRI was used to evaluate global and regional ventricular wall motion, as well as myocardial perfusion and infarction in a rat model. Our results show that the Intralipid ${ }^{\circledR}$ treatment following IRI can preserve global and regional ventricular wall motion, and reduce the infarct size. The Intralipid ${ }^{\circledR}$-treated rats exhibit reduced myocardial macrophage infiltration, indicating reduced in-situ myocardial inflammation. Conclusions: Our results indicate that the Intralipid ${ }^{\circledR}$ treatment can protect the heart against IRI and can specifically reduce in-situ myocardial inflammation. Additional study is needed to assess if treatment using Intralipid $^{\circledR}$ after LAD occlusion could improve the recovery of patients suffering from a heart attack and also reduce future development of heart failure.

\section{Keywords}

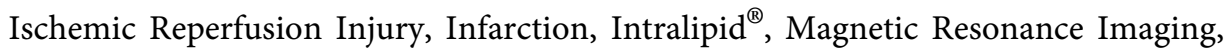


Macrophage/Monocyte

\section{Introduction}

Coronary heart disease (CHD) is a leading cause of death and disability, resulting in high health-care expenditures. Despite of the advancement of revascularization therapy and pharmacological thrombolysis, the long-term outcome of patients after acute myocardial infarction (MI) could be poor [1], due to myocardial ischemia-reperfusion injury (IRI) with resultant cardiomyocyte death and adverse long-term consequences [2] [3]. The abrupt restoration of circulation in the infarct-related artery not only brings in the much needed oxygen and nutrients, but also triggers inflammation and oxidative stress, which may cause greater damage to the tissue, and the subsequent adverse myocardial remodeling. As survival from acute myocardial infarction has improved due to the implementation of prompt revascularization therapy, improving long-term outcomes has arisen as an important goal. Patients who survive the initial event may suffer significant morbidity and mortality due to heart failure and adverse ventricular remodeling. Alternative interventions that can reduce IRI are needed.

Inflammation, especially inflammatory MØs, plays a central role in IRI [4]-[6]. Macrophages/monocytes (MØs) are the most common and crucial cardiac inflammatory cells in myocardial IRI [4] [6] [7], atherosclerosis [8] [9], MI [10], myocarditis [11], and cardiac transplantation [12]-[17]. Recently, it has been reported that negatively charged microparticles, synthesized from carboxylated polystyrene or poly(lactic-co-glycolic acid), can immune-modify MØs, reduce the infiltration of MØs to the sites of inflammation, and, thus, reduce the disease symptoms, e.g., cardiac IRI, kidney IRI, West Nile virus encephalitis, and inflammatory bowel disease [4] [18]. These negatively charged microparticles appear to be able to reduce the number of $\mathrm{CD}^{+} 8^{+}$or $\mathrm{ED} 1^{+} \mathrm{M} \emptyset$ s within the infarct area, thus reducing the infarction size, and enhance cardiac function.

Intralipid $^{\circledR}$, as a lipid emulsion and negatively charged microparticle, was approved by FDA in 1972. It has been used clinically as a parenteral nutrition source to provide patients with needed calories and essential fatty acids. Intralipid ${ }^{\circledR}$ exhibits a zeta potential $(\zeta)$ of $-34.45 \pm 8.115 \mathrm{mV}$ [19]. The diameter of the Intralipid ${ }^{\circledR}$ particles ranges from 200 to $1000 \mathrm{~nm}$ and the peak position is at $351 \mathrm{~nm}$ [19] [20]. Based on these results, we hypothesize that Intralipid ${ }^{\circledR}$ has the potential to derail MØs and change the trafficking of MØs in inflammatory heart diseases.

Intralipid $^{\circledR}$ has been shown to protect hearts against ischemic reperfusion injury to reduce infarct size after ischemic insult [21]-[23]. The cardioprotective mechanisms of Intralipid $^{\circledR}$ are not totally understood. It has been shown that Intralipid ${ }^{\circledR}$ can inhibit mitochondrial permeability transition pore opening [24] and reduce mitochondrial superoxide production, and increase pro-survival kinases such as Akt and GSK-3 [23] among other effects [4] [6] [7] [25] [26]. However, the effect of Intralipid ${ }^{\circledR}$ on post-MI inflammatory MØs has not been investigated. The goal of this study is to investigate the 
effects of Intralipid $^{\circledR}$ on the in-situ inflammation after IRI, as well as to characterize the functional outcomes of the Intralipid ${ }^{\circledR}$ treatment with an integrated cardiac magnetic resonance imaging (CMRI) approach in a pre-clinical rat model. Cellular MRI is used to visualize in-situ myocardial inflammation, whereas cardiac function and infarct are assessed by CMRI in vivo.

\section{Material and Methods}

\subsection{Animals}

Male Brown Norway $\left(\mathrm{BN} ; \mathrm{RT}^{\mathrm{n}}\right)$ rats were obtained from Harlan. Animal protocols were approved by the Institutional Animal Care and Use Committee of Carnegie Mellon University. All animals received humane care in compliance with the Guide for the Care and Use of Laboratory Animals.

\subsection{Animal Model, Preparation, and Treatment}

We employed a transient left anterior descending (LAD) artery occlusion model for creating IRI in rats [27]. Male inbred Brown Norway (BN; RT1 ${ }^{\mathrm{n}}$ ) rats, 2 to 3 months of age, weighing $250 \pm 30 \mathrm{~g}$, were subjected to general anesthesia with isoflorane. After induction via a nose cone, the animal was intubated and ventilated with $2 \%$ isoflorane in oxygen and nitrogen gas mixture with a tidal volume of $1.0 \mathrm{ml} / 100 \mathrm{~g}$ body weight at a rate of 55 - 60 strokes per minute. A rectal temperature was maintained at $37^{\circ} \mathrm{C}$ with a heating pad.

Thoracotomy through the fourth intercostal space was performed followed by pericardiotomy, to gain access to the heart and LAD. The LAD was temporarily ligated with 6-0 Prolene suture (Novafil). After $45 \mathrm{~min}$, the suture was removed to re-perfuse the heart, the chest wall was closed, and the animal was recovered from anesthesia and returned to its cage; or to be subjected to in-vivo CMRI.

At the onset of re-perfusion, Intralipid ${ }^{\circledR}(20 \%$, purchased from Fresenius Kabi) was intravenously administered at a dose of $2 \mathrm{~g} / \mathrm{kg}$. Control animals received saline. 16 rats were given Intralipid ${ }^{\circledR}$ and 14 were given saline (untreated). For in-vivo MRI procedures, animals were subjected to the same anesthesia procedure, with the core body temperature maintained at $36.8^{\circ} \mathrm{C}$ with warm air, along with constant ECG and respiration monitoring (SA Instruments).

\subsection{MPIO Labeling}

The micrometer-sized iron-oxide (MPIO) particles $(4.5 \mathrm{mg} / \mathrm{kg}$, from Bangs Laboratories) were administered by a direct intra-venous injection through a penal vein $1-2$ days prior to the ischemic-reperfusion procedure to label monocytes/macrophages in vivo, to assess the inflammation status of the myocardium by cellular MRI.

\subsection{In-Vivo MRI}

In-vivo MR imaging was carried out on a Bruker Biospec AV3 7T/21-cm system equipped with $12-\mathrm{cm}, 50$ Gauss $/ \mathrm{cm}$ shielded gradients with a $72-\mathrm{mm}$ bird-cage volume 
coil.

In-vivo Cellular MRI: $T_{2}^{*}$-weighted imaging was acquired with an ECG- and respiratory-gated-FLASH sequence, with 10 to 12 short-axis slices used to cover the whole volume of the heart with the following parameters: FOV $=4 \mathrm{~cm}$; slice thickness $=1.1$ $\mathrm{mm}$; in-plane resolution $=156 \mu \mathrm{m} ; \mathrm{TE}=5.5 \mathrm{~ms}$, and $\mathrm{TR}=1$ respiratory cycle, about 1 sec.

In-vivo Functional MRI: An INTRAGATE sequence was used to evaluate global systolic cardiac function, anatomical changes, and wall thinning over time. Cine MRI was acquired with the following parameters: $\mathrm{TE} / \mathrm{TR}=3.2 \mathrm{~ms} / 5.6 \mathrm{~ms}$; equivalent temporal resolution for the cine loops was about 16.5 - $19.5 \mathrm{~ms}$ per frame, with 20 to 26 cardiac phases per cardiac cycle with in-plane resolution $=156 \mu \mathrm{m}$.

Regional wall motion and strain were assessed by tagging MRI followed by strain analysis with HARP (Diagnosoft Inc.). Tagging was achieved by a modified SPAMM sequence, with both ECG and respiration gating; TR = one cardiac cycle (about 180 $\mathrm{ms}$ ); $\mathrm{TE}=3.2 \mathrm{~ms}$; with 20 to 26 frames per cardiac cycle, tag distance $=1 \mathrm{~mm}$.

Myocardial perfusion and infarction were measured by first-pass contrast-enhance dynamic and late-Gadolilium enhancement (LGE) with a single bolus Gd $(0.1 \mathrm{mmol} / \mathrm{kg}$ of ProHance, Bracco Diagnostics, Inc.) administration. Myocardial first-pass perfusion was evaluated using cine MRI acquired with an Intragate sequence with the following parameters: TE/TR $=3.2 \mathrm{~ms} / 5.6 \mathrm{~ms}$; FOV $=4 \mathrm{~cm}$; slice thickness $=2 \mathrm{~mm}$; in-plane resolution $=156 \mu \mathrm{m}$; frame rate $=18 \mathrm{sec}$ per $256 \times 256$ image frame. 80 end-diastolic $(\mathrm{ED})$ time-frames were acquired over the time course of $24 \mathrm{~min}$. A single-bolus Gd was injected at $5 \mathrm{~min}$ after the onset of the time series acquisition. Myocardial infarction was evaluated by the LGE from the same time series of the first-pass myocardial perfusion.

\subsection{Ex-Vivo Magnetic Resonance Microscopy (MRM)}

At the end point of the study, the animals were euthanized, the hearts were harvested and fixed in $4 \%$ paraformaldehyde. Fixed exercised hearts were imaged using a Bruker AVANCE DRX 11.7-T system with a Micro2.5 gradient insert. High-resolution 3D $T_{2}^{*}$ weighted MRM images were acquired with a TR/TE $=500 / 5.5 \mathrm{~ms}$, and a $36-\mu \mathrm{m}$ isotropic resolution.

\subsection{Strain and Wall-Motion Analysis}

Myocardial strain analysis was performed with HARP (http://www.diagnosoft.com/), based on the harmonic phase method in Fourier domain. Four consecutive mid-level short-axis slices out of the 10-slice stack were subjected to strain analysis. For regional strain analysis, each short-axis slice was divided into 6 regions: R1, anterioseptal; R2, inferiospetal; R3, inferior; R4, inferiolateral; R5, anteriolateral; and R6, anterior walls. The anterior attachment of the right ventricle (RV) to left ventricle (LV) was always chosen as the landmark for segment numbering. Strain values were presented as unit-less percentile of deformation compared to the reference phase (ED). 


\subsection{Flow-Cytometry Analysis}

Flow cytometry (FACSVantage, Becton Dickinson) was used to determine the percentage of MØs, lymphocytes, and NK cells in peripheral blood. Blood samples were taken from untreated IRI rats and Intralipid ${ }^{\circledR}$-treated IRI rats on day 1 and day 2 prior to sacrifice. The following antibodies and reagents were purchased from AbD Serotec: ED1, anti-rat CD68:AlexaFluor488 antibody labels MØs; W3/25:FITC/Ox-8:RPE, anti-rat CD4/CD8; Ox-6, anti-rat major histocompatibility complex class II, RT1.B:FITC (H2Alike) molecule; and BUF09. Ox-39, anti-rat CD25:PE was purchased from eBioscience. Data were processed with the FlowJo software (Tree Star, Inc.).

\subsection{Pathological Analysis and Whole-Slide Imaging (WSI)}

Excised hearts were fixed in $4 \%$ paraformaldehyde for 1 - 2 weeks and embedded in paraffin. $5-\mu \mathrm{m}$ transverse heart tissue sections were taken at the ischemic regions, and H\&E-stained slides were obtained. Immunohistochemistry was also conducted to label $\mathrm{ED} 1^{+}$macrophages using 1:200 anti-rat ED1 ${ }^{+}$monoclonal purified IgG (AbD SeroTec). The H\&E-stained slides and immunohistochemistry slides were scanned on a whole slide scanner (Nanozoomer 2.0-HT, Hamamatsu, Japan) to acquire WSI at 20x magnification. The whole-slide images were then processed by WS-Recognizer (http://ws-recognizer.labsolver.org) [28]. The cell nuclei in the H\&E-stained slides were recognized to calculate the cell density across the entire tissue section, whereas the $\mathrm{ED}^{+}$macrophages were recognized to calculate the spatial distribution of macrophages.

\subsection{Statistical Analysis}

Descriptive statistics were summarized as mean \pm standard errors or as median (interquartile range) as appropriate. Examination of normal distribution assumption for continuous data was determined by q-q plots, histograms and Shapiro-Wilk test. Two-sample independent $t$ test or Wilcoxon Mann-Whitney Rank Sum test was used to determine the differences between groups for normally or non-normally distributed continuous data, respectively. Adjustment for a multiple comparison for Wilcoxon Mann-Whitney test was performed using Sidak adjustment method. For Figure 7 data, adjustment for multiple hypotheses testing (six hypotheses) was performed using the Holm's method. P-values and adjusted p-values $\left(\mathrm{p}_{\mathrm{a}}\right)$ are presented.

\section{Results}

\subsection{In-Vivo CMRI Evaluation of the Functional Outcome of Intralipid ${ }^{\circledR}$ Treatment after IRI}

Cine MRI was used to quantify the ejection fraction (EF) from Intralipid ${ }^{\circledR}$-treated and control rats in the acute phase following IRI. Figure 1 shows the representative end-diastolic (ED) and end-systolic (ES) images from an un-treated rat (Figure 1(A) \& Figure 1(B), respectively) and an Intralipid ${ }^{\circledR}$-treated rat (Figure $1(\mathrm{C})$ \& Figure 1(D), respectively). A plot of the temporal changes in the left-ventricular volume (LVV) for 6 

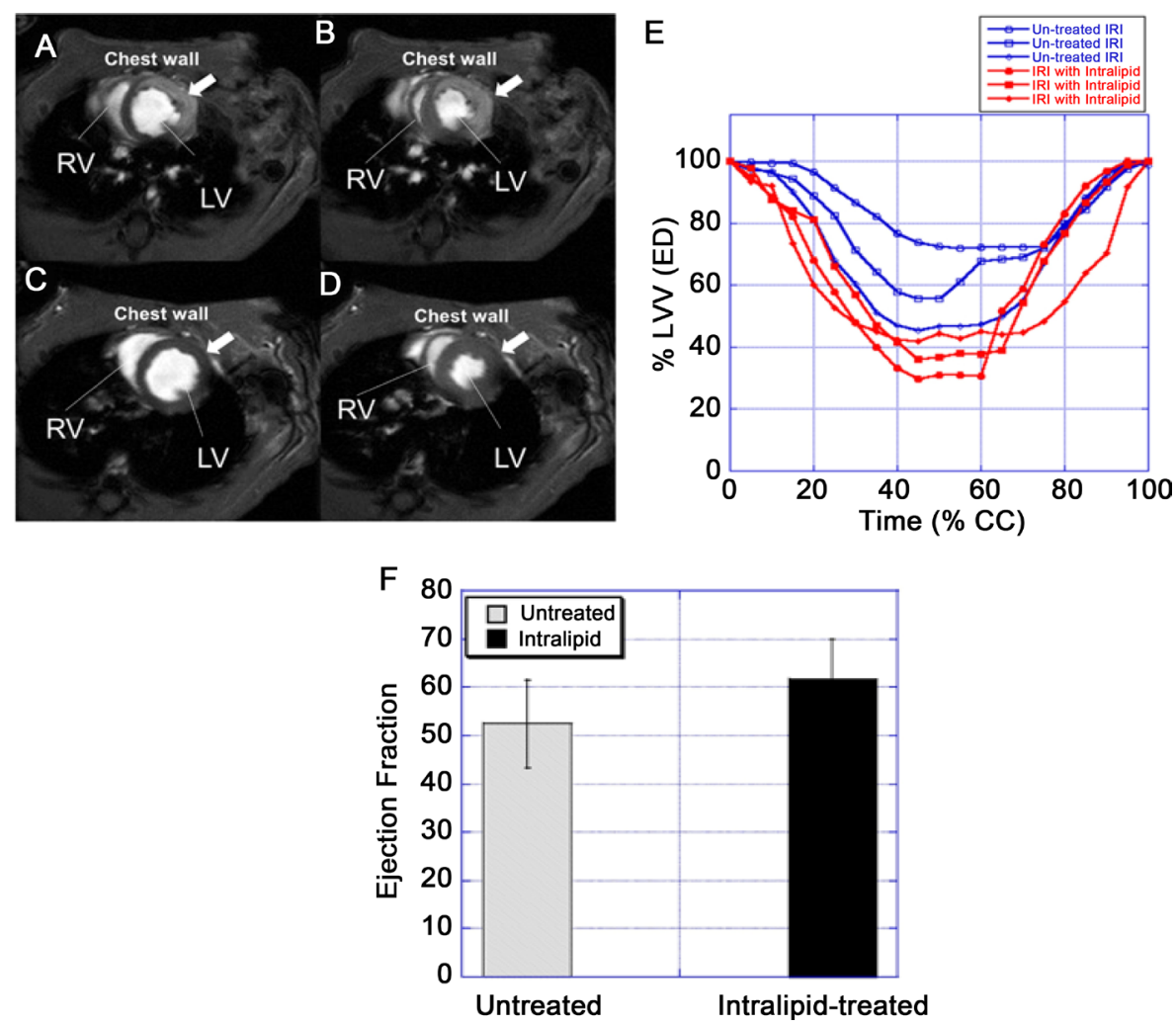

Figure 1. In-vivo cine MRI of ((A), (B)) untreated and ((C), (D)) Intralipid ${ }^{\circledR}$-treated hearts at ((A), (C)) end-diastole and ((B), (D)) end-systole; (E) temporal changes of LV volume of 3 untreated animals (open blue circles, squares, and diamonds) and 3 Intralipid ${ }^{\circledR}$-treated animals across different cardiac phases through a cardiac cycle (filled red circles, squares, and diamonds); and $(\mathrm{F})$ averaged ejection fraction for the untreated IRI hearts (gray bar, $\mathrm{n}=13$ ) and the Intralipid $^{\circledR}$-treated IRI hearts (black bar, $\mathrm{n}=16$ ). Error bars represented are standard errors. LV: left-ventricle; RV: right ventricle; the white arrowheads point to the ischemic injury site.

subjects (3 untreated animals and 3 Intralipid $^{\circledR}$-treated animals) (Figure 1(E)) demonstrates a clear improvement in the LV function following the acute Intralipid ${ }^{\circledR}$ treatment. Over all, immediate treatment with Intralipid ${ }^{\circledR}$ following a 45-min LAD artery occlusion and reperfusion is found to significantly enhance the EF performance by over $17 \%$, from $52.4 \% \pm 9.1 \%$ to $61.6 \% \pm 8.4 \%(\mathrm{p}=0.0086)$.

Myocardial tagging [29]-[31] and strain analysis [32] [33] were used to quantify the regional myocardial function following IRI and the acute response to Intralipid ${ }^{\circledR}$ treat- $^{2}$ ment. Figure 2 shows the representative images of the tagging-MRI for the same subjects shown in Figure 1. ED and ES tagging images for an untreated rat are shown in Figure 2(A) and Figure 2(B), respectively, and the Intralipid ${ }^{\circledR}$-treated subject in Figure 2(D) and Figure 2(E), respectively. Color encoded circumferential strain (Ecc) maps are shown in Figure 2(C) and Figure 2(F) for the untreated and the Intralipid $^{\circledR}$-treated rats, respectively.

After transient ischemic insult followed by re-perfusion, although the coronary blood flow is restored, and the hearts with IRI regain good EF (Figure 1), the myocardium is injured due to IRI (Figure 2). The untreated IRI heart (Figure 2(A), Figure 2(B)) 
shows impaired wall motion of the ischemic injury site. The injured anterial lateral wall (Figure 2(C), and Figure 2(G) gray bars) exhibits greatly reduced Ecc. With the Intralipid $^{\circledR}$ treatment (Figure 2(D), Figure 2(E) and Figure 2(G) gray bars), in addition to restored EF, the Intralipid ${ }^{\circledR}$-treated IRI heart shows preserved ventricular wall motion (Figure 2(D), Figure 2(E)) and improved strain (Figure 2(F), Figure 2(G)). The wall-motion abnormality appears to be centered around the injury site (Figure 2(A), Figure 2(B), Figure 2(G)) and the remote myocardium on the septal wall seems to be intact (Figure 2(A), Figure 2(B), Figure 2(G)). Some wall abnormality is observed in the peri-infarct regions next to the ischemic injury site (Figure 2(A), Figure 2(B), Figure 2(G)).

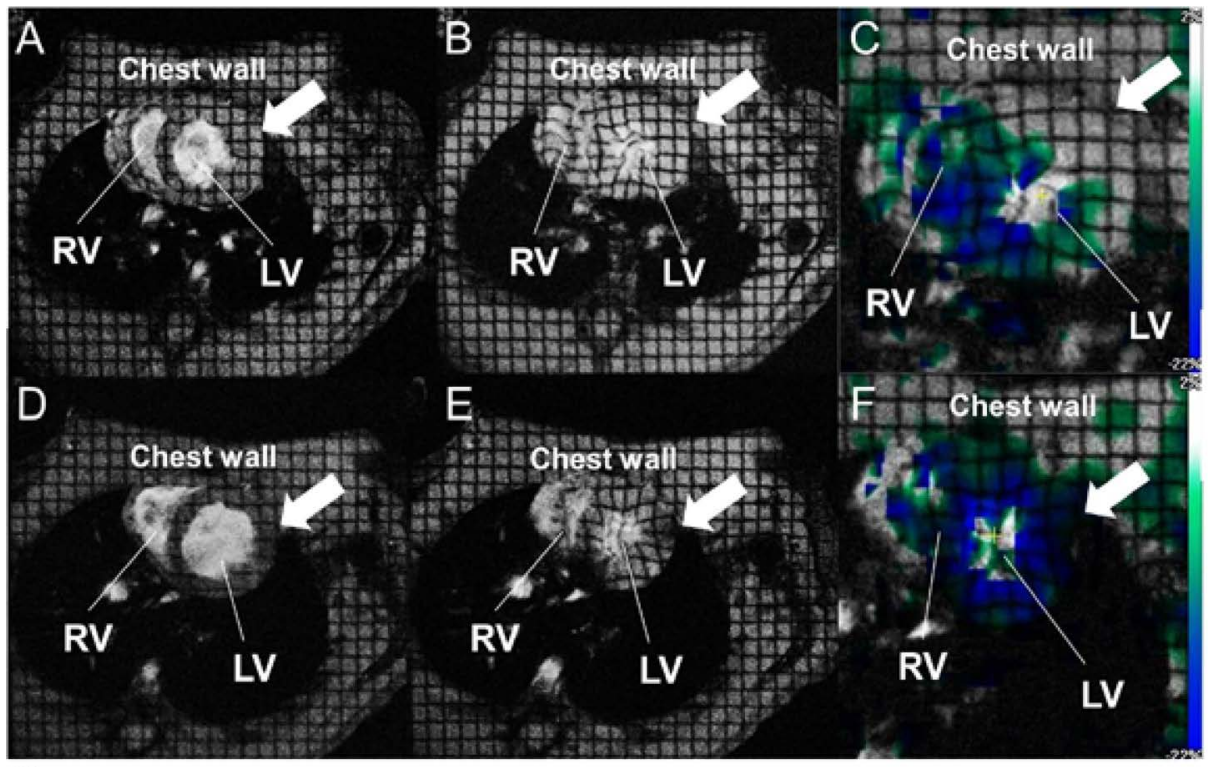

G

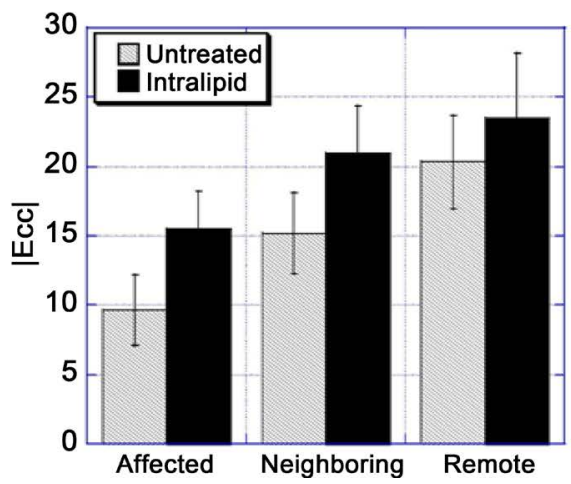

Figure 2. Evaluation of the ventricular wall motion by tagging MRI ((A), (B), (D), (E)) and strain analysis ((C), (F)): tagging MRI for an untreated IRI heart ((A), (B)) and an Intralipid ${ }^{\circledR}$-treated IRI heart ((D), (E)) at end-diastole ((A), (D)) and end-systole ((B), (E)); ((C), (F)) corresponding circumferential strain (Ecc) maps of this untreated IRI heart (C) and the Intralipid ${ }^{\circledR}$-treated IRI heart (F). The white arrowheads point to the ischemic injury sites. LV: left-ventricle; RV: right ventricle. $(\mathrm{G})$ mean absolute circumferential strain (Ecc) values for the untreated IRI hearts (gray bars, $n=9$ ) and the Intralipid ${ }^{\circledR}$-treated IRI hearts (black bars, $n=9$ ), for the ischemic injury affected heart segments, neighboring segments, or remote segments. 
Strain analysis [32] [33] has been used to quantify the regional wall motion detected by tagging MRI (Figure 2(C), Figure 2(F), Figure 2(G)). Conventional 6-segment model of a short-axis mid-ventricular level is used to quantify the strain. After ischemic-reperfusion insult, both untreated and Intralipid ${ }^{\circledR}$-treated hearts show impaired and reduced strain at the ischemic site (Figure $2(G)$, "affected" segments). Intralipid ${ }^{\circledR}$ treated hearts preserve some wall-motion capacity and exhibit better strain than the untreated group. The differences in Ecc between untreated $(9.64 \pm 0.85)$ and intralipid $^{\circledR}$-treated groups $(15.49 \pm 0.92)$ at the ischemic site (2G, "affected" segments), and at the peri-injury myocardial areas ( $2 \mathrm{G}$, "neighboring" segments) between the untreated $(15.23 \pm 0.98)$ and the Intralipid ${ }^{\circledR}$-treated $(20.94 \pm 1.13)$, were found to be statistically significant $(\mathrm{p}<0.01)$. The regional wall motion of the remote myocardium near septal and inferio-septal wall regions (2G, "remote" segments) show less affected wall motion.

Free-breathing no-gating first-pass contrast enhanced dynamic MRI with a single Gd bolus (Figure 3 ) and the LGE is used to access the myocardial perfusion and to evaluate the extent of infarction in vivo (Figure $3(\mathrm{G})$ ). The untreated IRI hearts shows impaired myocardial perfusion at the IRI site (Figures $3(\mathrm{~A})-(\mathrm{C})$ ) and the areas with LGE (Figure 3(B), Figure 3(C), and Figure 3(G)). With Intralipid ${ }^{\circledR}$ treatment (Figures 3(D)-(F)), the myocardial perfusion is improved and the infarct size is reduced (Figure $3(\mathrm{G})$ ). There is a statistically significant difference between the underlying distributions of the infarct size for the untreated and the infarct size for the intralipid ${ }^{\circledR}$-treated groups (Wilcoxon statistic $=264, \mathrm{n}_{1}=16, \mathrm{n}_{2}=13, p=0.0056$ ).

\subsection{In-Vivo Cellular MRI Evaluation of Mø Trafficking at the IRI Site upon Intralipid ${ }^{\circledR}$ Treatment}

After a transient ischemia, although blood flow is fully restored, inflammation has already set in. MØs infiltrated to the injured myocardium can be detected in-vivo as the hypointensity area on the $T_{2}^{*}$-weighted MRI with iron-oxide particle labeling [13] [16] [17]. After the in-vivo MPIO labeling, the hypointensity can be detected in the IRI site of myocardium (Figures 4(A)-(C) and Figure 4(G)) with the in-vivo $T_{2}^{*}$-weighted MRI, indicating the accumulation of MPIO-labeled MØs. With Intralipid ${ }^{\circledR}$ treatment, the myocardial hypointensity is greatly decreased (Figures $4(D)$-(F) and Figure 4(G)), indicating a reduced in-situ myocardial inflammation.

Percentage of the myocardium that contains image hypointensity (Figure 4(G)), obtained by in-vivo $T_{2}^{*}$ MRI, is calculated to quantify the degree MPIO-labeled M $\emptyset$ infiltration in the heart, as a measurement of in-situ inflammation. In-vivo $T_{2}^{*}$ cellular MRI evaluated on the day of ischemic surgery ("day 0" groups) as well as after 1 to 5 days (" $<1$ week" groups). The difference between the underlying distributions of the area for the untreated and the areas for the intralipid ${ }^{\circledR}$-treated groups both for "day 0 " (Wilcoxon statistic $=39.50, \mathrm{n}_{1}=7, \mathrm{n}_{2}=14, \mathrm{p}=0.0112, \mathrm{p}_{\mathrm{a}}=0.0223$ ) and a few days after ischemic insult (Wilcoxon statistic $=45.00, \mathrm{n}_{1}=6, \mathrm{n}_{2}=19, \mathrm{p}=0.0494, \mathrm{p}_{\mathrm{a}}=0.0964$ ) were found to be statistically significant. 

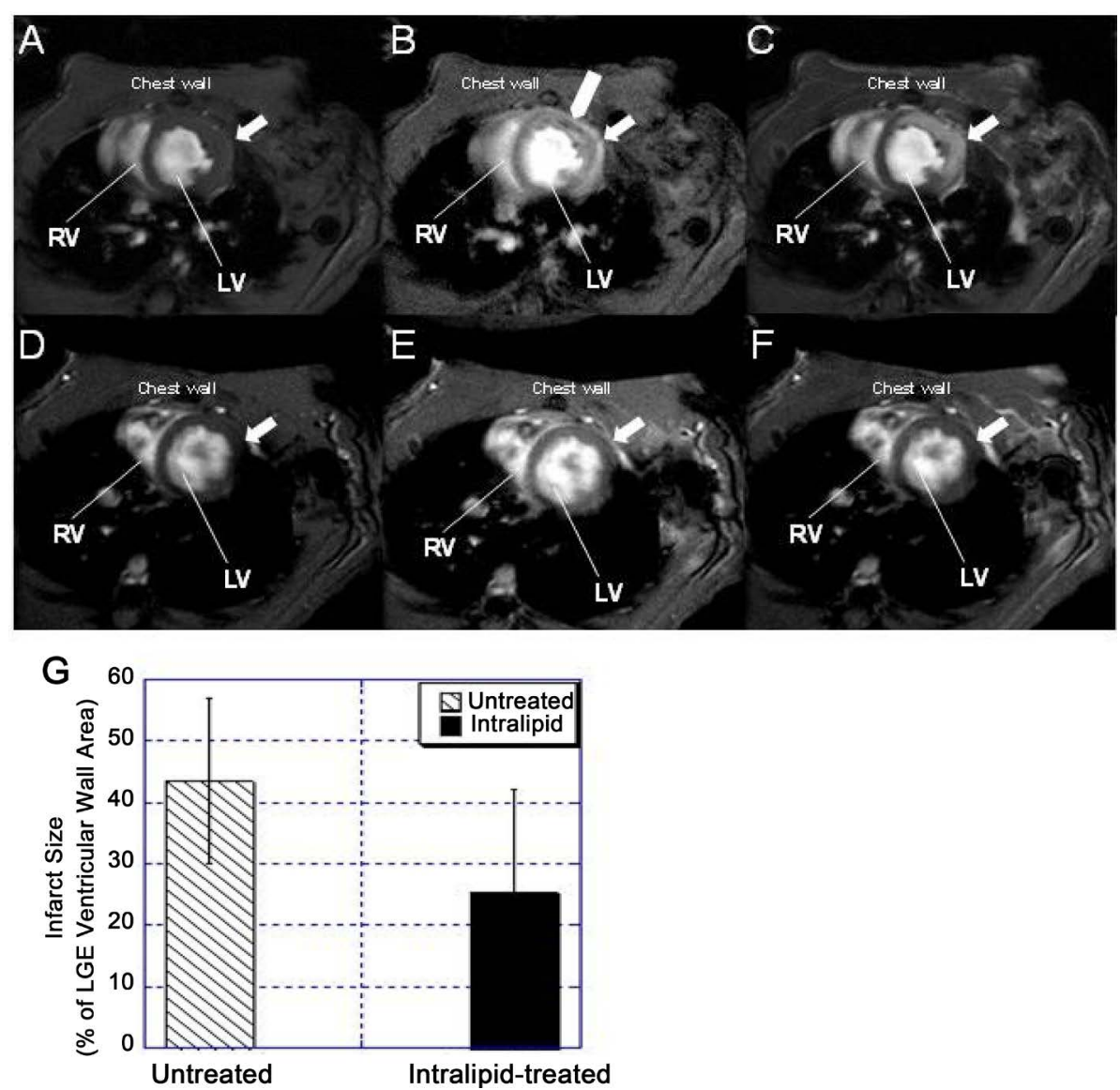

Figure 3. In-vivo quantification of the infarct size by late-Gadolilium enhancement (LGE) and first-pass myocardial perfusion of an untreated IRI heart ((A)-(C)) and an Intralipid ${ }^{\circledR}$-treated IRI heart ((D)-(F)) taken prior to Gd contrast ((A), (D)), $43 \mathrm{sec}$ after a single Gd bolus injection, and ((C), (F)) 16-min post-Gd bolus. The white arrowheads point to the area with IRI. The white tab in (B) points to the infarct core. LV: left-ventricle; RV: right ventricle. (G) Infarct size quantified by the percentage of LV area with LGE of the untreated IRI hearts (striped bar, $n=13$ ) and the Intralipid ${ }^{\circledR}$-treated IRI hearts (black bar, $\mathrm{n}=16$ ).

\subsection{Ex-Vivo MRM}

The hearts were harvested at the end-point of the study for high-resolution ex-vivo MRM (Figure 5). At this imaging resolution, single MPIO-labeled MØs can be visualized as individually resolved dark spots [16]. All hearts examined showed low-level sparse distribution of dark spots throughout the heart, which are non-specific background infiltration of MPIO-labeled MØs. This sparse background infiltration of MØs may function as a surveillance for inflammation. In addition to this background of sparse infiltration, the untreated heart (Figure 5(A)) showed concentrated hypointensity in the ischemic site, which is composed of individual dark spots, as well as dark streaks. Individual dark spots are MPIO-labeled MØs [16] infiltrated in the ischemic site, whereas the dark streaks are likely to be hemorrhage in the infarct core. On the other hand, Intralipid ${ }^{\circledR}$-treated IRI hearts showed reduced hypointensity. In the example shown in Figure 5(B), both infiltration of MPIO-labeled MØs and hemorrhage in 

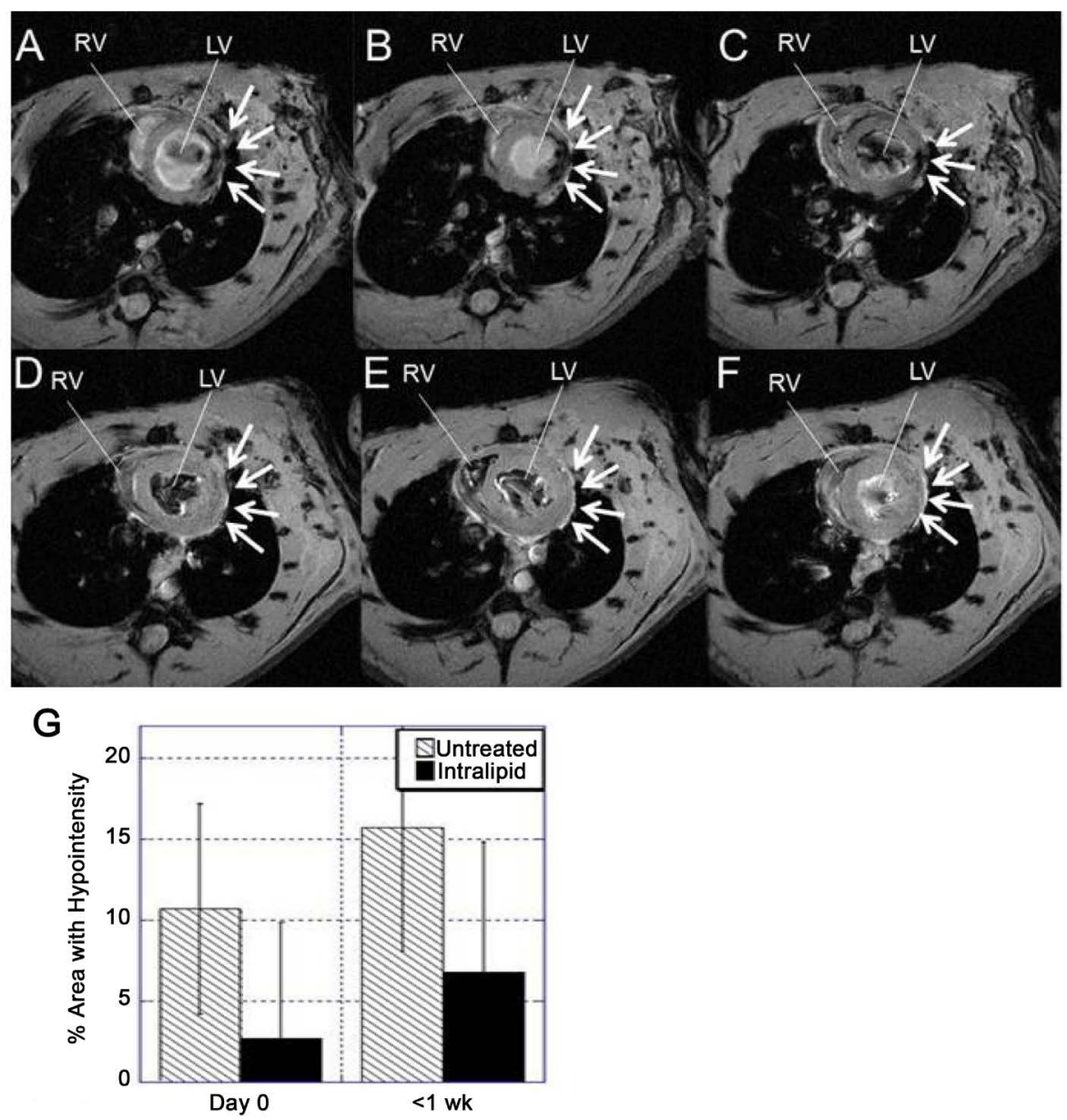

Figure 4. In-vivo cellular MRI of IRI hearts 2 days after a transient ischemic injury and in-vivo MPIO labeling of the untreated animals ((A)-(C)) and the Intralipid ${ }^{\circledR}$-treated animals ((D)-(F)). White arrowheads point to the areas with IRI injury. The $T_{2}^{*}$-weighted images were acquired at 7-Tesla with $156-\mu \mathrm{m}$ in-plane resolution. (G) Percentage of areas with hypointensity in myocardium for untreated IRI animals (striped bars) or Intralipid ${ }^{\circledR}$-treated IRI animals (black bars) on the day of ischemic insult (day 0 ) or 1 to 5 days after IRI ( $<1 \mathrm{wk}$ ). Animal numbers included in the study were 14 for the untreated group and 7 for the Intralipid ${ }^{\circledR}$-treated for the "day 0 " groups. 19 untreated animals and 6 Intralipid ${ }^{\circledR}$-treated animals were included for the " $<1$ wk" group.

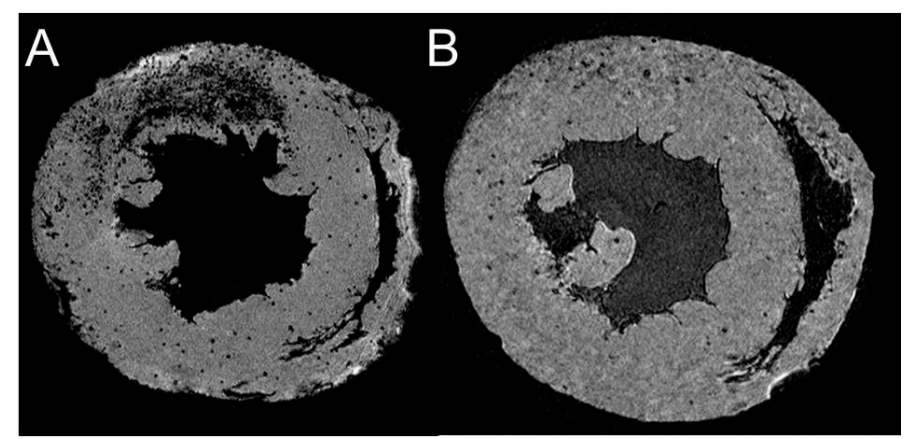

Figure 5. Ex-vivo MR microscopy (MRM) of the hearts harvested 2 days after a transient ischemic injury and in-vivo MPIO labeling of an untreated animal (A) or an Intralipid ${ }^{\circledR}$-treated animal (B). MRM is acquired with $36-\mu \mathrm{m}$ isotropic resolution at $11.7 \mathrm{~T}$. 
the infarct core are reduced.

\subsection{Pathological Examination}

Figure 6 shows the pathology images of the untreated (Figures 6(A)-(D)) and Intralipid $^{\circledR}$-treated group (Figures $6(\mathrm{E})-(\mathrm{H})$ ). The untreated group presents a substantial increase of the immune cells in the ischemic myocardium. Figure 6(A) shows the cell-density distribution of the tissue sections on the H\&E slide. The distribution reveals a prominent increase of the cell density at the ischemic injury region in the sham group. Figure 6(B) shows the distribution of $\mathrm{ED1}^{+} \mathrm{M} \emptyset \mathrm{s}$ of the same animal. The distribution also reveals a prominent increase of the $M \varnothing$ infiltration in the ischemic tissue. Figure $6(\mathrm{C})$ illustrates a view in the H\&E slide, showing the infiltration of immune cells in the myocardium. The immunohistochemistry shown in Figure 6(D) confirms that the infiltrating cells are $\mathrm{ED} 1^{+} \mathrm{MØs.} \mathrm{The} \mathrm{Intralipid}{ }^{\circledR}$ group also presents an increase of the immune cells in the ischemic myocardium, but the cell density is substantially less than the sham group. Figure 6(E) shows the cell-density distribution of the tissue sections on the H\&E slide, whereas Figure 6(F) shows the distribution of ED1 $1^{+} \mathrm{M} \emptyset$ s of the same animal. The density of the infiltrating cells is substantially less than the sham group. Figure $6(\mathrm{G})$ illustrates a view in the H\&E slide, whereas Figure $6(\mathrm{H})$ illustrates a view in the $\mathrm{ED1}^{+}$stain slides. The density of the immune cells is less than the sham group, suggesting that Intralipid $^{\circledR}$ reduces the amount of MØs infiltrating into the ischemic myocardium.
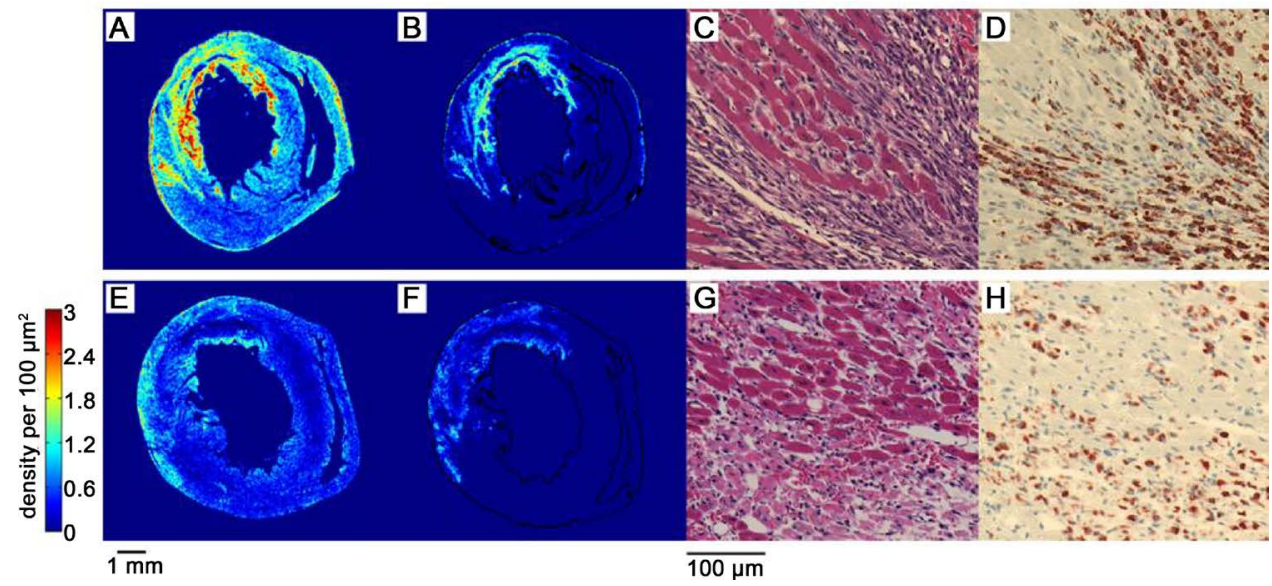

Figure 6. MR pathology images comparing the cell distribution of the myocardium in the sham and Intralipid ${ }^{\circledR}$-treated group: (A) the cell density in the H\&E-slide of a sham animal shows a prominent increase of cell density due to ischemic injury by WSI; (B) the $\mathrm{ED} 1^{+} \mathrm{M} \emptyset$ distribution of the same sham animal shows the spatial distribution of the infiltrating $M \emptyset$ in the ischemic myocardium by WSI; (C) the H\&E image of the myocardium of the sham animal illustrates the infiltrating cells; (D) the immune-stain image confirms that the infiltrating cells are $\mathrm{ED} 1^{+} \mathrm{M} \emptyset$; (E) the cell density in the H\&E-slide of an Intralipid ${ }^{\circledR}$-treated animal shows less density than the sham animal by WSI; (F) the ED1 ${ }^{+} \mathrm{M} \emptyset$ distribution of the same animal also shows fewer MØs in the ischemic myocardium by WSI; (G) the H\&E image of the Intralipid ${ }^{\circledR}$-treated animal shows fewer cells than the shame group; and (H) the immuno-staining image shows less ED1 ${ }^{+} \mathrm{MØs}$ of the Intralipid ${ }^{\circledR}$-treated animal. 
One limitation of the cellular MRI is that both hemorrhage and MPIO-labeled MØs show hypointensity in $T_{2}^{*}$-weighted MRI. We cannot distinguish the blood clots from the infiltrated labeled MØs in the heart in vivo. EX-vivo high-resolution $T_{2}^{*}$-weighted MRM (Figure 5) revealed that the hypointensed area detected in the in-vivo $T_{2}^{*}$ weighted MRI are composed of a "core" with continuous dark area, probably the hemorrhage of the infarct core, and the individual dark "dots", are probably MPIO-labeled MØs. One single dot is likely to be one labeled MØ [16]. Pathological examinations (Figure 6) have confirmed that these are $\mathrm{ED} 1^{+} \mathrm{MØs}$ and blood. Although in-vivo $T_{2}^{*}$-weighted MRI cannot distinguish labeled MØs and hemorrhage, both are reduced with Intralipid ${ }^{\circledR}$ treatment after IRI.

\subsection{Flow Cytometry Study}

On day 1 after IRI, we have found that Intralipid $^{\circledR}$ can decrease the circulating ED1 ${ }^{+}$ MØs dramatically in the peripheral blood (Figure $7(\mathrm{~A})$ and Figure $7(\mathrm{~B})$ ). On day 2, although the in-situ $\mathrm{M} \varnothing$ infiltration is greatly reduced by the Intralipid ${ }^{\circledR}$ treatment $^{-}$ (Figure 4 and Figure 6), the composition of $M \varnothing$ and other types of immune cells, including helper T-lymphocytes (CD4), cytotoxic T-cells (CD8), TL- $2 \alpha$ receptor containing cells (CD25), Class II antigen-presenting cells (RT1B), NK cells (CD 161), in the peripheral blood show no different with or without Intralipid ${ }^{\circledR}$ treatment (Figure 7(C) and Figure $7(\mathrm{D}))$. No statistically significant differences in CD4 $\left(\mathrm{p}=0.4162, \mathrm{p}_{\mathrm{a}}=\right.$ 1.000), CD8 ( $\left.p=0.3024, p_{a}=1.000\right), \operatorname{CD} 25\left(p=0.3024, p_{a}=1.000\right), R T 1 B(p=0.1234$, $\left.\mathrm{p}_{\mathrm{a}}=1.000\right), \mathrm{CD} 161\left(\mathrm{p}=0.5557, \mathrm{p}_{\mathrm{a}}=1.000\right)$, and ED1 $\left(\mathrm{p}=0.8119, \mathrm{p}_{\mathrm{a}}=1.000\right)$ were found between the two groups.

\section{Discussions}

As survival from acute myocardial infarction has improved due to the implementation of prompt revascularization therapy, improving the long-term outcomes has arisen as an important goal. Patients who survive the initial event could suffer significant morbidity and mortality due to adverse ventricular remodeling resulting in the long-term heart failure. Acute myocardial IRI is the major cause of the adverse effects of CHD on the myocardium [2]. Our results demonstrate that Intralipid ${ }^{\circledR}$ indeed can protect the resulting injury in hearts due to IRI as shown by our in-vivo non-invasive multi-parameter CMRI in a rat model of acute myocardial infaction. With a single intravenous Intralipid $^{\circledR}$ administration after LAD occlusion, rats treated with Intralipid $^{\circledR}$ show a marked improvement of cardiac function, both global systolic function, such as EF, stroke volumes, and cardiac output, as well as regional ventricular wall motion and strain in vivo. Our results show that the Intralipid ${ }^{\circledR}$ treatment also greatly reduces the size of infarcted and "at risk" myocardium after IRI.

Previously, conflicting results were reported regarding whether Intralipid ${ }^{\circledR}$ could protect the heart against ischemic insult or not [21] [22] [25] [26]. It is known that the pressure and the volume loading of the heart are important for the response to IRI [34]. Although important conclusions were drawn, some of the previous functional mea- 

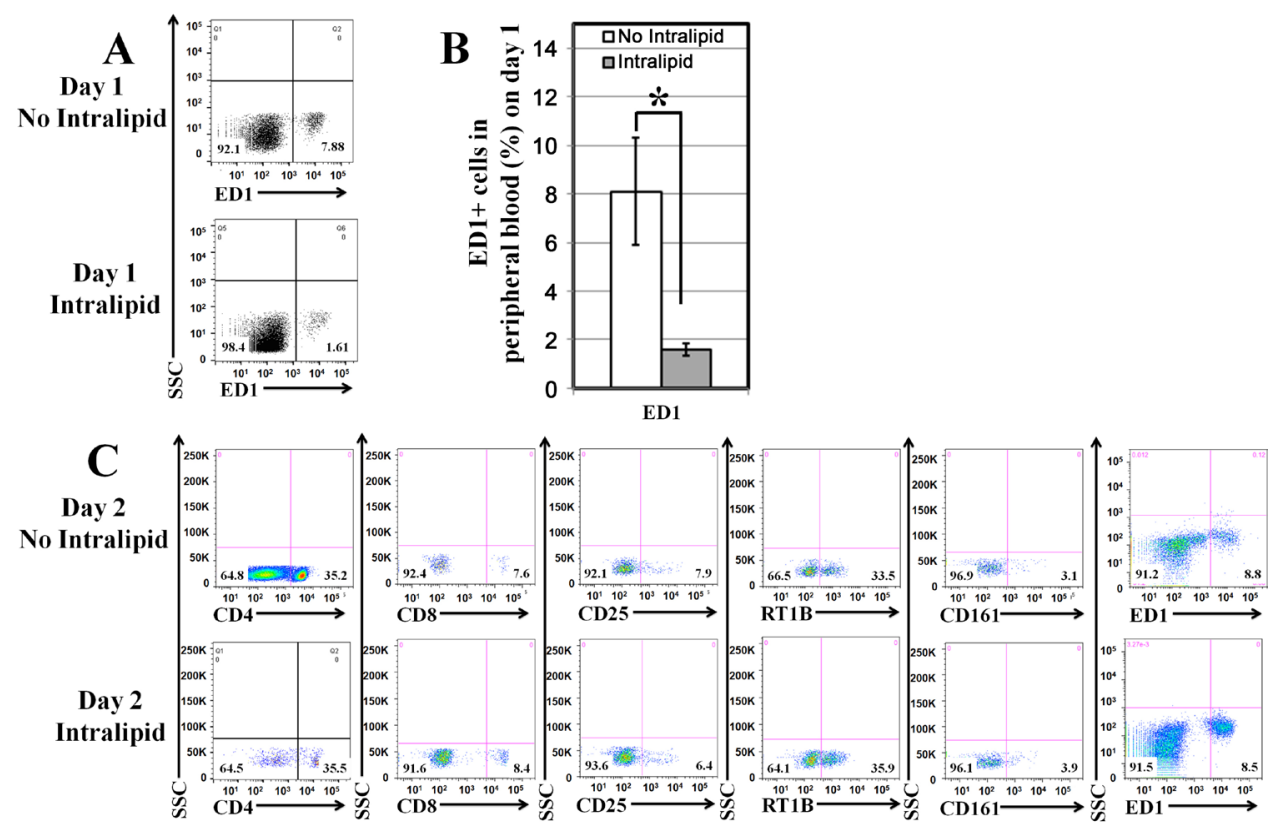

D

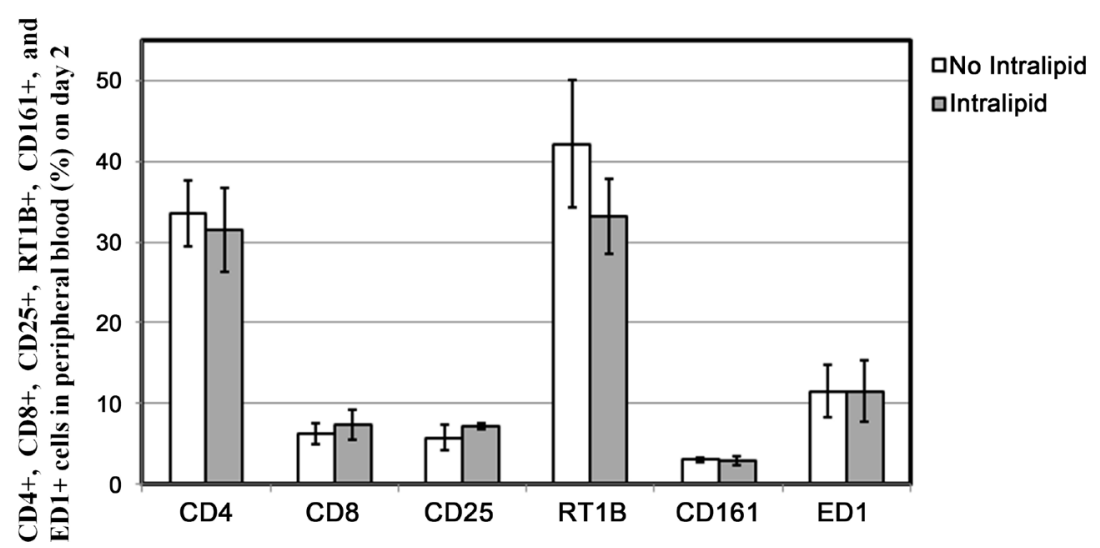

Figure 7. Flow cytometry analysis of the changes of immune cells in peripheral blood upon Intralipid ${ }^{\circledR}$ treatment after LAD occlusion: (A) representative flow cytometry dot plots showing

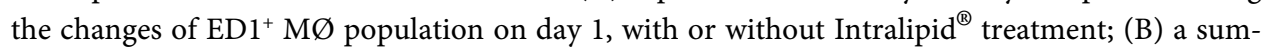
mary bar figure of the data shown in (A); (C) representative flow cytometry dot plots of CD4, CD8, CD25, RT1B, CD 161, and ED1 positive cells in peripheral blood on day 2, with or without Intralipid ${ }^{\circledR}$ treatment; and (D) a summary chart of the data shown in $(C) .{ }^{\star} p<0.01$. No statistically significant differences in any of the markers tested (CD4, CD8, CD25, RT1B, CD161 and ED1) on day 2 were found between the two groups.

surements for Intralipid ${ }^{\circledR}$ 's cardio-protective effects were done in isolated Langendorffperfused heart preparation or by an invasive pressure measurement of hemodynamics. Here, we have measured the ventricular function in the intact physiological context with a multi-parameter in-vivo CMR approach, which provides reliable evaluation of the functional outcomes.

Inflammation plays a central role in IRI and inflammatory MØs are one of the key players [4] [6]. The amplitude of inflammation and the timely resolution affect the post-MI repair and remodeling [35] [36]. Post-inschemic myocardial inflammation is a 
complex process. Neutrophils arrive early peaking within $24 \mathrm{hr}$ post-injury, followed by monocytes/macrophages. Macrophages are key modulator and effector cells in immune response [37]. Different macrophage classes, $\mathrm{M}_{1}, \mathrm{M}_{2}$, and $\mathrm{M}_{\mathrm{reg}}$, play different roles in IRI at different time [37]-[41]. Initial macrophage involvement and inflammation are harmful, peaking around 3 to 5 days post-ischemia, triggering necrotic myocardium loss and subsequent adverse myocardial remodeling. On the other hand, later macrophage involvement after 7 days is essential for wound healing and recovery from IRI [42] [43]. We have previously shown that myocardial inflammation and macrophage infiltration can be correctly and specifically detected in vivo with cellular MRI by iron-oxide particle labeling of macrophages [13]-[17]. The hypointensity detected by $T_{2}^{*}$-weighted MRI arises from ED1+ macrophages. The extent of hypointensity correctly reflected the degree of myocardial inflammation [13]. In this study, we have used in-vivo cellular MRI for macrophages as a reporter index to reflect the myocardial inflammation status; in particular, the pro-inflammatory harmful macrophages within the initial 5 days post-ischemic insult [4].

The mechanisms of how Intralipid ${ }^{\circledR}$ mediates cardio-protection in IRI are not well understood. Intralipid $^{\circledR}$ s cardio-protective effect is likely to be multi-facets, which could include Salvage kinase or other receptor-mediated pathways [22], inhibiting mitochondrial permeability transition pore opening [24], reducing mitochondrial superoxide production, increasing pro-survival kinases such as Akt and GSK-3 [23], reducing calcium overload, as well as a metabolic switch [44] from glucose to fatty acid fuels for the ischemic heart. The effect of Intralipid ${ }^{\circledR}$ on myocardial inflammatory $M \varnothing$ has not been investigated. Our results show that, in addition to these intra-myocyte cascades, Intralipid ${ }^{\circledR}$ can also reduce in-situ myocardial inflammation after IRI. In this study, we have found that negatively charged microparticle, Intralipid ${ }^{\circledR}$, can significantly reduce the infiltration of $\mathrm{CD}^{+} 8^{+}$or $\mathrm{ED} 1^{+} \mathrm{M} \emptyset \mathrm{s}$. $\mathrm{M} \emptyset$ infiltration into the injured myocardium is evaluated by in-vivo and ex-vivo $\mathrm{T}_{2}{ }^{*}$-MRI, and validated by immunohistochemistry. It is consistent with the findings of Getts et al. [4] that, $24 \mathrm{hr}$ after the treatment of negatively charged microparticles, the number of $\mathrm{ED} 1^{+} \mathrm{M} \emptyset$ s in peripheral blood decreased. To our best knowledge, this is the very first demonstration of Intralipid $^{\circledR}$ 's ability to reduce in-situ inflammation in the intact heart.

Interestingly, on day 2, even though the in-situ inflammation in the heart is reduced, there are no significant changes in the leukocyte composition in circulation with the common markers used for MØs, T-cells, and antigen-presenting cells (CD4, CD8, CD25, RT1B, CD161 and ED1). Our results show the dis-association of the in-situ inflammation status in the heart from the systemic blood marker in circulation. Therefore, in-vivo cellular MRI provides an invaluable tool to non-invasively access the in-situ inflammation status in its intact physiological context that cannot be accurately determined by a general blood-panel evaluation.

After the ischemic cardiac injury, a robust inflammation response is activated to remove necrotic heart tissue and to promote healing. This immune response after IRI is highly coordinated and dynamic [45]. If this indicates that the interaction between the 
immune system and the heart is perturbed, negative consequences can result. Early pre-clinical findings indicated that anti-inflammatory corticosteroids treatment could decrease infarct size [46] and led to clinical trials using anti-inflammatory agents, such as methylprednisolone, to treat MI patients [47], but resulted in a catastrophic outcome. It is now known that inflammation can play dual roles after IRI. Myocardial inflammation is both detrimental and reparative. A general non-specific abolishing of inflammation may be harmful to the injured cardiac tissue. It is now known that there are heterogenic phenotypes of $\mathrm{M} \varnothing$ sub-classes that mediate different functions at different times. Inflammatory monocytes or classically activated M1 MØs accumulate early, in the first hours of reperfusion, and are thought to be harmful to the tissue. On the other hand, "resident" or "reparative" monocytes are also known as alternatively activated M2 MØs that appear later, after 5 to 7 days after IRI, and are thought to be important

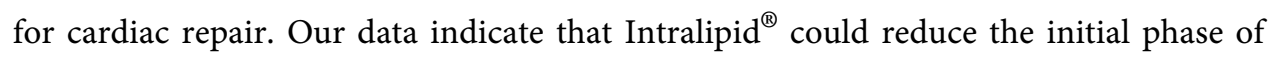

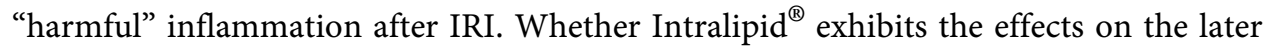
"reparative" phase of inflammation needs further investigation.

Immune cells, particularly macrophages and monocytes, are emerging therapeutic targets, however, the non-invasive clinical tools for assessing their presence in the myocardium are lacking [48] [49]. The systemic biomarkers in peripheral blood might not reflect the inflammation status in the myocardium. Diagnostic imaging tools that can access myocardial inflammation will be very beneficial in this endeavor [48] [50] [51]. In-vivo cellular MRI provides a valuable tool to investigate the intricate interplays of innate immune system and the heart, which is important for developing suitable therapeutic strategies for ischemic heart diseases, and other pathological conditions.

One major difference in the animal IRI models and human patients with coronary artery syndromes is that $\mathrm{CHD}$ patients are often having chronically elevated inflammation prior to the ischemic event, whereas the experimental animals do not have elevated in-situ inflammation until the contrary artery occlusion occurs. The immune system status could be different. Whether Intralipid ${ }^{\circledR}$ can reduce in-situ myocardial inflammation in the human CHD patients need further clinical studies. Interestingly, it has been reported that Intralipid ${ }^{\circledR}$ infusion might inhibit foam cell formation [52] and block the activity of lysophosphatidylcholine [53], which is a major lipid component of the oxidized low density lipoproteins, thus benefit CHD patients.

We have investigated if a pre-treatment of Intralipid ${ }^{\circledR}$ prior to the ischemic insult can improve the cardio-protective effects of Intralipid ${ }^{\circledR}$, but the result is negative. There is no statistically significant difference between the underlying distributions of Ecc for the pre-IRI treatment $(n=8)$ receiving Intralipid ${ }^{\circledR}$ one hour prior to the ischemic insult and that for the post-IRI groups $(n=6)$ receiving Intralipid ${ }^{\circledR}$ at the onset of reperfusion (Wilcoxon statistic $=48, \mathrm{n}_{1}=8, \mathrm{n}_{2}=6, p=0.7520$ ). Pre-treatment of Intralipid ${ }^{\circledR}$ does not show detectable functional or cellular differences, compared to the IRI hearts that were treated with Intralipid ${ }^{\circledR}$ after the ischemic insult.

Iron-oxide-nano-particles are cleared quickly by the reticuloendothelial system. In general, Iron-oxide-particles have short blood half-life, depending on their size and 
surface coating materials [17]. We have shown [54] that the pre-treatment of Intralipid $^{\circledR}$ prior to iron-oxide particle administration can temporarily inhibit Kupper cells in the liver, increase its blood half-life, thus, improve labeling efficiency. For the present study, MPIO was given 1-to-3 days prior to the ischemic surgery. MPIO's in-vivo blood half-life in rodents only lasts a few minutes [16] [54], so MPIO particles are cleared from the circulation at the time of ischemic surgery, Intralipid ${ }^{\circledR}$ treatment, and the subsequent in-vivo CMRI measurements. Therefore, the changes in the in-situ MØ infiltration after the Intralipid ${ }^{\circledR}$ treatment observed with MRI are not due to changes in the labeling efficiency of MPIO. Pathological evaluation confirmed that $\mathrm{ED} 1^{+}$staining of all MØs in the heart did decrease with Intralipid ${ }^{\circledR}$ treatment.

Pathology and immune-histochemical evaluations of the tissue are essential in validating the cellular and functional MRI results. However, the conventional pathology examination limits the view to a very small area on the target tissue. Selection and grading of the field-of-interest can be subjective and biased. The WSI method that we have developed provides an overall and quantitative evaluation of the whole pathology slide without pre-selecting field-of-interest [28]. The computational detection algorithm provides an objective and quantitative evaluation of the true pathological evaluation of the tissue. Our WSI results (Figure 6) indicate that Intralipid ${ }^{\circledR}$ did indeed decrease $\mathrm{ED}^{+} \mathrm{M} \varnothing$ infiltration in the IRI heart, confirming our cellular MRI finding.

Although it has generally been presumed that the infarct size and the efficacy of the initial treatment are key determinants of the down-stream heart failure and the adverse remodeling, the role of ischemia reperfusion injury is less well characterized. It is possible that the initial IRI may set forth a pathologic cascade that impacts the long-term outcomes. Further study is needed to assess whether the treatments designed to limit IRI may also reduce future development of heart failure. Intralipid ${ }^{\circledR}$ is a safe and broadly used nutritional supplement, and therefore an excellent model treatment to test this approach. Insights gained may set the stage for translational trials to determine if Intralipid $^{\circledR}$ may be an effective treatment for IRI in the clinical setting, and whether this therapy can improve the outcomes by reducing pathological remodeling and progression of heart failure following myocardial infarction.

\section{Acknowledgements}

We thank Mr. Brent Barbe for carrying surgical procedures as well as Mr. Yehuda Creeger, Ms. Wendy F. Li, and Ms. Lanya Tseng for their assistance in flow cytometry experiments. We thank Dr. Anil V. Parwani of the Department of Pathology of University of Pittsburgh Medical Center for providing the whole slide scanner for our work.

The work was supported by grants from the National Institutes of Health (P41EB001977 and UL1TR000005).

\section{References}

[1] Ezekowitz, J.A., Kaul, P., Bakal, J.A., Armstrong, P.W., Welsh, R.C. and McAlister, F.A. 
(2009) Declining In-Hospital Mortality and Increasing Heart Failure Incidence in Elderly Patients with First Myocardial Infarction. Journal of the American College of Cardiology, 53, 13-20. http://dx.doi.org/10.1016/j.jacc.2008.08.067

[2] Hausenloy, D.J., Bøtker, H.E., Condorelli, G., Ferdinandy, P., Garcia-Dorado, D., Heusch, G., Lecour, S., van Laake, L.W., Madonna, R., Ruiz-Meana, M., Schulz, R., Sluijter, J.P., Yellon, D.M. and Ovize, M. (2013) Translating Cardioprotection for Patient Benefit: Position Paper from the Working Group of Cellular Biology of the Heart of the European Society of Cardiology. Cardiovascular Research, 98, 7-27. http://dx.doi.org/10.1093/cvr/cvt004

[3] Ibáñez, B., Heusch, G., Ovize, M. and Van de Werf, F. (2015) Evolving Therapies for Myocardial Ischemia/Reperfusion Injury. Journal of the American College of Cardiology, 65, 1455-1471. http://dx.doi.org/10.1016/j.jacc.2015.02.032

[4] Getts, D.R., Terry, R.L., Getts, M.T., Deffrasnes, C., Muller, M., van Vreden, C., Ashhurst, T.M., Chami, B., McCarthy, D., Wu, H., Ma, J., Martin, A., Shae, L.D., Witting, P., Kansas, G.S., Kuhn, J., Hafezi, W., Campbell, I.L., Reilly, D., Say, J., Brown, L., White, M.Y., Cordwell, S.J., Chadban, S.J., Thorp, E.B., Bao, S., Miller, S.D. and King, N.J. (2014) Therapeutic Inflammatory Monocyte Modulation Using Immune-Modifying Microparticles. Science Translational Medicine, 6, 219ra7. http://dx.doi.org/10.1126/scitranslmed.3007563

[5] Christodoulou, A.G., Zhao, B., Zhang, H., Ho, C. and Liang, Z.-P. (2011) Four-Dimensional MR Cardiovascular Imaging: Method and Applications. Annual International Conference of the IEEE Engineering in Medicine and Biology Society, Boston, 30 August-3 September 2011, 3732-3735. http://dx.doi.org/10.1109/iembs.2011.6090635

[6] Frangogiannis, N.G., Smith, C.W. and Entman, M.L. (2002) The Inflammatory Response in Myocardial Infarction. Cardiovascular Research, 53, 31-47. http://dx.doi.org/10.1016/S0008-6363(01)00434-5

[7] Li, X., Mikhalkova, D., Gao, E., Zhang, J., Myers, V., Zincarelli, C., Lei, Y.H., Song, J.L., Koch, W.J., Peppel, K., Cheung, J.Y., Feldman, A.M. and Chan, T.O. (2011) Myocardial Injury after Ischemia-Reperfusion in Mice Deficient in Akt2 Is Associated with Increased Cardiac Macrophage Density. American Journal of Physiology-Heart and Circulatory Physiology, 301, H1932-H1940. http://dx.doi.org/10.1152/ajpheart.00755.2010

[8] Mulder, W.J., Jaffer, F.A., Fayad, Z.A. and Nahrendorf, M. (2014) Imaging and Nanomedicine in Inflammatory Atherosclerosis. Science Translational Medicine, 6, $239 \mathrm{sr} 1$. http://dx.doi.org/10.1126/scitranslmed.3005101

[9] Fredman, G., Kamaly, N., Spolitu, S., Milton, J., Ghorpade, D., Chiasson, R., Kuriakose, G., Perretti, M., Farokhzad, O. and Tabas, I. (2015) Targeted Nanoparticles Containing the Proresolving Peptide Ac2-26 Protect against Advanced Atherosclerosis in Hypercholesterolemic Mice. Science Translational Medicine, 7, $275 \mathrm{ra} 20$.

http://dx.doi.org/10.1126/scitranslmed.aaa1065

[10] Nahrendorf, M., Pittet, M.J. and Swirski, F.K. (2010) Monocytes: Protagonists of Infarct Inflammation and Repair after Myocardial Infarction. Circulation, 121, 2437-2445. http://dx.doi.org/10.1161/CIRCULATIONAHA.109.916346

[11] Fairweather, D. and Cihakova, D. (2009) Alternatively Activated Macrophages in Infection and Autoimmunity. Journal of Autoimmunity, 33, 222-230. http://dx.doi.org/10.1016/j.jaut.2009.09.012

[12] Kanno, S., Wu, Y.J., Lee, P.C., Dodd, S.J., Williams, M., Griffith, B.P. and Ho, C. (2001) Macrophage Accumulation Associated with Rat Cardiac Allograft Rejection Detected by Magnetic Resonance Imaging with Ultrasmall Superparamagnetic Iron Oxide Particles. Circulation, 104, 934-938. http://dx.doi.org/10.1161/hc3401.093148

[13] Wu, Y.L., Ye, Q., Eytan, D.F., Liu, L., Rosario, B.L., Hitchens, T.K., Yeh, F.C., Rooijen van, 
N. and Ho, C. (2013) Magnetic Resonance Imaging Investigation of Macrophages in Acute Cardiac Allograft Rejection after Heart Transplantation. Circulation: Cardiovascular Imaging, 6, 965-973. http://dx.doi.org/10.1161/CIRCIMAGING.113.000674

[14] Ye, Q., Wu, Y.L., Foley, L.M., Hitchens, T.K., Eytan, D.F., Shirwan, H. and Ho, C. (2008) Longitudinal Tracking of Recipient Macrophages in a Rat Chronic Cardiac Allograft Rejection Model with Noninvasive Magnetic Resonance Imaging Using Micrometer-Sized Paramagnetic Iron Oxide Particles. Circulation, 118, 149-156.

http://dx.doi.org/10.1161/CIRCULATIONAHA.107.746354

[15] Wu, Y.L., Ye, Q., Sato, K., Foley, L.M., Hitchens, T.K. and Ho, C. (2009) Noninvasive Evaluation of Cardiac Allograft Rejection by Cellular and Functional Cardiac Magnetic Resonance. JACC: Cardiovascular Imaging, 2, 731-741. http://dx.doi.org/10.1016/j.jcmg.2009.01.013

[16] Wu, Y.L., Ye, Q., Foley, L.M., Hitchens, T.K., Sato, K., Williams, J.B. and Ho, C. (2006) In Situ Labeling of Immune Cells with Iron Oxide Particles: An Approach to Detect Organ Rejection by Cellular MRI. Proceedings of the National Academy of Sciences of the United States of America, 103, 1852-1857. http://dx.doi.org/10.1073/pnas.0507198103

[17] Wu, Y.L., Ye, Q. and Ho, C. (2011) Cellular and Functional Imaging of Cardiac Transplant Rejection. Current Cardiovascular Imaging Reports, 4, 50-62.

http://dx.doi.org/10.1007/s12410-010-9055-3

[18] Harrison, C. (2014) Monocytes Derailed by Microparticles. Nature Reviews Drug Discovery, 13, 175. http://dx.doi.org/10.1038/nrd4263

[19] Bhatt, N., Prasad, R.K., Singh, K. and Panpalia, G.M. (2010) Stability Study of O/W Emulsions Using Zeta Potential. Journal of Chemical and Pharmaceutical Research, 2, 512-527.

[20] Hansen, L.M., Hardie, B.S. and Hidalgo, J. (1976) Fat Emulsion for Intravenous Administration: Clinical Experience with Intralipid(R) 10\%. Annals of Surgery, 184, 80-88. http://dx.doi.org/10.1097/00000658-197607000-00014

[21] Liu, S.L., Wang, Y., Wang, R.R., Chai, Y.F., Wu, W., Huang, H. and Liu, J. (2008) Protective Effect of Intralipid on Myocardial Ischemia/Reperfusion Injury in Isolated Rat Heart. Chinese Critical Care Medicine, 20, 227-230.

[22] Rahman, S., Li, J., Bopassa, J.C., Umar, S., Iorga, A., Partownavid, P. and Eghbali, M. (2011) Phosphorylation of GSK-3 $\beta$ Mediates Intralipid-Induced Cardioprotection against Ischemia/Reperfusion Injury. Anesthesiology, 115, 242-253.

http://dx.doi.org/10.1097/ALN.0b013e318223b8b9

[23] Lou, P.H., Lucchinetti, E., Zhang, L., Affolter, A., Schaub, M.C., Gandhi, M., Hersberger, M., Warren, B.E., Lemieux, H., Sobhi, H.F., Clanachan, A.S. and Zaugg, M. (2014) The Mechanism of Intralipid(R)-Mediated Cardioprotection Complex IV Inhibition by the Active Metabolite, Palmitoylcarnitine, Generates Reactive Oxygen Species and Activates Reperfusion Injury Salvage Kinases. PLoS ONE, 9, e87205. http://dx.doi.org/10.1371/journal.pone.0087205

[24] Li, J., Iorga, A., Sharma, S., Youn, J.Y., Partow-Navid, R., Umar, S., Cai, H., Rahman, S. and Eghbali, M. (2012) Intralipid, a Clinically Safe Compound, Protects the Heart against Ischemia-Reperfusion Injury More Efficiently than Cyclosporine-A. Anesthesiology, 117, 836-846. http://dx.doi.org/10.1097/ALN.0b013e3182655e73

[25] Hu, Z.Y., Luo, N.F. and Liu, J. (2009) The Protective Effects of Emulsified Isoflurane on Myocardial Ischemia and Reperfusion Injury in Rats. Canadian Journal of Anesthesia, 56, 115-125. http://dx.doi.org/10.1007/s12630-008-9016-3

[26] Rao, Y., Wang, Y.L., Chen, Y.Q., Zhang, W.S. and Liu, J. (2009) Protective Effects of Emulsified Isoflurane after Myocardial Ischemia-Reperfusion Injury and Its Mechanism in Rab- 
bits. Chinese Journal of Traumatology, 12, 18-21.

[27] Klocke, R., Tian, W., Kuhlmann, M.T. and Nikol, S. (2007) Surgical Animal Models of Heart Failure Related to Coronary Heart Disease. Cardiovascular Research, 74, 29-38. http://dx.doi.org/10.1016/j.cardiores.2006.11.026

[28] Yeh, F.C., Parwani, A.V., Pantanowitz, L. and Ho, C. (2014) Automated Grading of Renal Cell Carcinoma Using Whole Slide Imaging. Journal of Pathology Informatics, 5, 23. http://dx.doi.org/10.4103/2153-3539.137726

[29] Axel, L. and Dougherty, L. (1989) Heart Wall Motion: Improved Method of Spatial Modulation of Magnetization for MR Imaging. Radiology, 172, 349-350.

http://dx.doi.org/10.1148/radiology.172.2.2748813

[30] Kraitchman, D.L., Young, A.A., Chang, C.N. and Axel, L. (1995) Semi-Automatic Tracking of Myocardial Motion in MR Tagged Images. IEEE Transactions on Medical Imaging, 14, 422-433. http://dx.doi.org/10.1109/42.414606

[31] Young, A.A., Kraitchman, D.L., Dougherty, L. and Axel, L. (1995) Tracking and Finite Element Analysis of Stripe Deformation in Magnetic Resonance Tagging. IEEE Transactions on Medical Imaging, 14, 413-421. http://dx.doi.org/10.1109/42.414605

[32] Osman, N.F. and Prince, J.L. (2004) Regenerating MR Tagged Images Using Harmonic Phase (HARP) Methods. IEEE Transactions on Biomedical Engineering, 51, 1428-1433. http://dx.doi.org/10.1109/TBME.2004.827932

[33] Castillo, E., Osman, N.F., Rosen, B.D., El-Shehaby, I., Pan, L., Jerosch-Herold, M., Lai, S., Bluemke, D.A. and Lima, J.A. (2005) Quantitative Assessment of Regional Myocardial Function with MR-Tagging in a Multi-Center Study: Interobserver and Intraobserver Agreement of Fast Strain Analysis with Harmonic Phase (HARP) MRI. Journal of Cardiovascular Magnetic Resonance, 7, 783-791. http://dx.doi.org/10.1080/10976640500295417

[34] Mozaffari, M.S., Liu, J.Y., Abebe, W. and Baban, B. (2013) Mechanisms of Load Dependency of Myocardial Ischemia Reperfusion Injury. American Journal of Cardiovascular Disease, 3, 180-196.

[35] Libby, P., Tabas, I., Fredman, G. and Fisher, E.A. (2014) Inflammation and Its Resolution as Determinants of Acute Coronary Syndromes. Circulation Research, 114, 1867-1879. http://dx.doi.org/10.1161/CIRCRESAHA.114.302699

[36] Frangogiannis, N.G. (2012) Regulation of the Inflammatory Response in Cardiac Repair. Circulation Research, 110, 159-173. http://dx.doi.org/10.1161/CIRCRESAHA.111.243162

[37] Martinez, F.O. and Gordon, S. (2014) The M1 and M2 Paradigm of Macrophage Activation: Time for Reassessment. F1000Prime Reports, 6, 13. http://dx.doi.org/10.12703/P6-13

[38] Lee, S., Huen, S., Nishio, H., Nishio, S., Lee, H.K., Choi, B.S., Ruhrberg, C. and Cantley, L.G. (2011) Distinct Macrophage Phenotypes Contribute to Kidney Injury and Repair. Journal of the American Society of Nephrology, 22, 317-326. http://dx.doi.org/10.1681/ASN.2009060615

[39] Mosser, D.M. and Edwards, J.P. (2008) Exploring the Full Spectrum of Macrophage Activation. Nature Reviews Immunology, 8, 958-969. http://dx.doi.org/10.1038/nri2448

[40] Fleming, B.D. and Mosser, D.M. (2011) Regulatory Macrophages: Setting the Threshold for Therapy. European Journal of Immunology, 41, 2498-2502. http://dx.doi.org/10.1002/eji.201141717

[41] Mannon, R.B. (2012) Macrophages: Contributors to Allograft Dysfunction, Repair, or Innocent Bystanders? Current Opinion in Organ Transplantation, 17, 20-25. http://dx.doi.org/10.1097/MOT.0b013e32834ee5b6 
[42] Bajwa, A., Kinsey, G.R. and Okusa, M.D. (2009) Immune Mechanisms and Novel Pharmacological Therapies of Acute Kidney Injury. Current Drug Targets, 10, 1196-1204. http://dx.doi.org/10.2174/138945009789753174

[43] Jang, H.S., Kim, J., Park, Y.K. and Park, K.M. (2008) Infiltrated Macrophages Contribute to Recovery after Ischemic Injury but Not to Ischemic Preconditioning in Kidneys. Transplantation, 85, 447-455.

[44] Riess, M.L. and Podgoreanu, M.V. (2013) Intralipid: The New Magic Bullet in Cardioprotection? Anesthesiology, 118, 1237-1238. http://dx.doi.org/10.1097/ALN.0b013e31828bac35

[45] Epelman, S. and Mann, D.L. (2012) Communication in the Heart: The Role of the Innate Immune System in Coordinating Cellular Responses to Ischemic Injury. Journal of Cardiovascular Translational Research, 5, 827-836. http://dx.doi.org/10.1007/s12265-012-9410-7

[46] Libby, P., Maroko, P.R., Bloor, C.M., Sobel, B.E. and Braunwald, E. (1973) Reduction of Experimental Myocardial Infarct Size by Corticosteroid Administration. Journal of Clinical Investigation, 52, 599-607. http://dx.doi.org/10.1172/JCI107221

[47] Roberts, R., DeMello, V. and Sobel, B.E. (1976) Deleterious Effects of Methylprednisolone in Patients with Myocardial Infarction. Circulation, 53, I204-I206.

[48] Leuschner, F., Rauch, P.J., Ueno, T., Gorbatov, R., Marinelli, B., Lee, W.W., Dutta, P., Wei, Y., Robbins, C., Iwamoto, Y., Sena, B., Chudnovskiy, A., Panizzi, P., Keliher, E., Higgins, J.M., Libby, P., Moskowitz, M.A., Pittet, M.J., Swirski, F.K., Weissleder, R. and Nahrendorf, M. (2012) Rapid Monocyte Kinetics in Acute Myocardial Infarction Are Sustained by Extramedullary Monocytopoiesis. The Journal of Experimental Medicine, 209, 123-137. http://dx.doi.org/10.1084/jem.20111009

[49] Weissleder, R., Nahrendorf, M. and Pittet, M.J. (2014) Imaging Macrophages with Nanoparticles. Nature Materials, 13, 125-138. http://dx.doi.org/10.1038/nmat3780

[50] Majmudar, M.D. and Nahrendorf, M. (2012) Cardiovascular Molecular Imaging: The Road Ahead. Journal of Nuclear Medicine, 53, 673-676. http://dx.doi.org/10.2967/jnumed.111.099838

[51] Nahrendorf, M., Sosnovik, D.E., French, B.A., Swirski, F.K., Bengel, F., Sadeghi, M.M., Lindner, J.R., Wu, J.C., Kraitchman, D.L., Fayad, Z.A. and Sinusas, A.J. (2009) Advances in Cardiovascular Imaging: Multimodality Cardiovascular Molecular Imaging, Part II. Circulation: Cardiovascular Imaging, 2, 56-70. http://dx.doi.org/10.1161/CIRCIMAGING.108.839092

[52] Aviram, M., Williams, K.J., McIntosh, R.A., Carpentier, Y.A., Tall, A.R. and Deckelbaum, R.J. (1989) Intralipid Infusion Abolishes Ability of Human Serum to Cholesterol-Load Cultured Macrophages. Arteriosclerosis, 9, 67-75. http://dx.doi.org/10.1161/01.ATV.9.1.67

[53] Coutant, F., Agaugue, S., Perrin-Cocon, L., Andre, P. and Lotteau, V. (2004) Sensing Environmental Lipids by Dendritic Cell Modulates Its Function. The Journal of Immunology, 172, 54-60. http://dx.doi.org/10.4049/jimmunol.172.1.54

[54] Liu, L., Hitchens, T.K., Ye, Q., Wu, Y., Barbe, B., Prior, D.E., Li, W.F., Yeh, F.C., Foley, L.M., Bain, D.J. and Ho, C. (2013) Decreased Reticuloendothelial System Clearance and Increased Blood Half-Life and Immune Cell Labeling for Nano- and Micron-Sized Superparamagnetic Iron-Oxide Particles upon Pre-Treatment with Intralipid. Biochimica et Biophysica Acta (BBA)-General Subjects, 1830, 3447-3453.

http://dx.doi.org/10.1016/j.bbagen.2013.01.021 
Submit or recommend next manuscript to SCIRP and we will provide best service for you:

Accepting pre-submission inquiries through Email, Facebook, LinkedIn, Twitter, etc.

A wide selection of journals (inclusive of 9 subjects, more than 200 journals)

Providing 24-hour high-quality service

User-friendly online submission system

Fair and swift peer-review system

Efficient typesetting and proofreading procedure

Display of the result of downloads and visits, as well as the number of cited articles

Maximum dissemination of your research work

Submit your manuscript at: http://papersubmission.scirp.org/

Or contactwjcd@scirp.org 